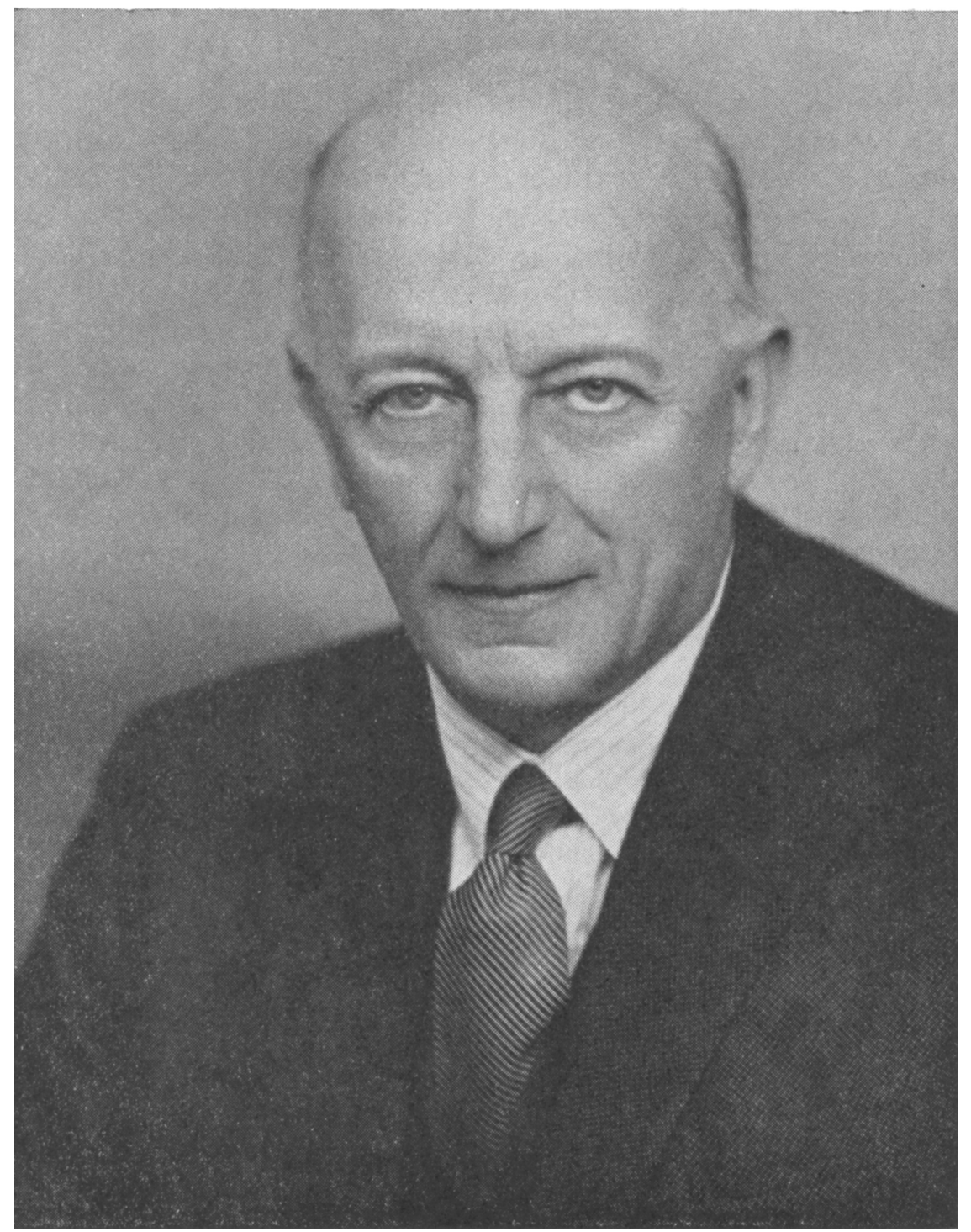

Elliott and Fry Ltd.

Sir EDWARD CollingwoOd 1900-1970 


\section{Obituary: SIR EDWARD COLLINGWOOD}

The death of Sir Edward Collingwood, F.R.S. on 25 October 1970 has left his numerous friends with a profound sense of loss. Of none will this be truer than of his fellow Trustees on the board of the Applied Probability Trust, whose Chairman he had been since its foundation in 1963. As Editor of the Trust's three publications, the Journal of Applied Probability, the Advances in Applied Probability, and Mathematical Spectrum, I had come to rely heavily on Sir Edward's mathematical judgment and administrative experience, both of them invaluable, particularly during the first few years of the Trust's existence.

Sir Edward was born in Northumberland on 17 January 1900 and was educated at the Royal Naval College, Osborne and Dartmouth. He served in the Royal Navy during the First World War, and on being invalided out in the following year went up to Trinity College, Cambridge, to read Mathematics. During his studies there, he won the Rayleigh Prize and the Rouse Ball Travelling Studentship. From 1930 until 1938 he was a lecturer in the Faculty of Mathematics at Cambridge University.

During the Second World War he first served in the Royal Naval Volunteer Reserve, and later rose to be Chief Scientist, Admiralty Mine Design Department in 1945. Throughout his varied career, he maintained the strongest interest in Mathematics and mathematicians; from 1960 to 1969 he served the mathematical community splendidly as Treasurer of the London Mathematical Society. He was elected Fellow of the Royal Society in 1965, and President of the London Mathematical Society in 1970.

But during these busy years he succeeded in retaining his interests in wider issues, and in 1963 he became Chairman of the Council of Durham University, and also Chairman of the Central Health Services Council. He also served as Treasurer of the Medical Research Council from 1960 to 1967.

Throughout his career, Sir Edward successfully interwove three strands of activity rarely found combined in one person: the mathematical, the administrative, and the humanitarian. He was a mathematician of distinction whose work had considerable impact on analysis; he wrote several papers on Nevanlinna theory and cluster sets, and in 1966 published the monograph The Theory of Cluster Sets with his friend A. J. Lohwater.

He was also a born administrator. His wisdom and foresight contributed much to the development of the University of Durham, and to the enlightened support of first class research by the Medical Research Council. To the London Mathema- 
tical Society he gave, during his term of office as Treasurer, a sound financial basis. For the Applied Probability Trust he provided from his wide knowledge of human affairs, invaluable advice both financial and organisational.

But, at least to me, it was the humanitarian in him which seemed the most noteworthy. His ideals of service to the community were of the very highest, his encouragement and courtesy to fellow workers unfailing. To discuss Trust problems and reach towards their solutions with him over the past seven years has been a rare privilege and inspiration. If an enterprise was projected to serve the mathematical community, no effort was too great to ensure its achievement, and no difficulty too daunting to discourage him. His understanding, good humour, and fundamental humanity evoked in all his colleagues a profound affection and respect.

Sir Edward's counsel will be sorely missed on the board of the Applied Probability Trust. Without his initial support the Trust might never have been founded; now that it is firmly established, it will continue to serve the mathematical community in the paths so clearly traced by Sir Edward Collingwood.

\section{J. Gani}

Department of Probability and Statistics University of Sheffield 